Running Head: communication of behaviour change interventions

\title{
'Communication of behaviour change interventions: can they be recognised from written descriptions?'
}

Marie Johnston: Institute of Applied Health Sciences, College of Life Science and Medicine, University of Aberdeen, $2^{\text {nd }}$ Floor, Health Sciences Building, AB25 2ZD, UK.

m.johnston@abdn.ac.uk Orcid.org/0000-0003-0124-4827 Twitter: mariejohnstonx

Derek Johnston: Institute of Applied Health Sciences, College of Life Science and Medicine, University of Aberdeen, $2^{\text {nd }}$ Floor, Health Sciences Building, AB25 2ZD, UK.

d.johnston@abdn.ac.uk

Caroline E Wood: Centre for Behaviour Change, Department of Clinical, Educational and Health Psychology, University College London, 1-19 Torrington Place, London, WC1E 7HB, UK.

caroline.wood@ucl.ac.uk

Wendy Hardeman ${ }^{1}$ :Behavioural Science Group, Primary Care Unit, Institute of Public Health, Forvie Site, University of Cambridge, School of Clinical Medicine Box 113, Cambridge Biomedical Campus, Cambridge CB2 OSR, UK.

w.hardeman@uea.ac.uk Orcid.org/0000-0002-6498-9407

Jill Francis: School of Health Sciences, City University of London, Northampton Square, London, EC1V OHB. UK.

Jill.Francis.1@city.ac.uk

Susan Michie: Centre for Behaviour Change, Department of Clinical, Educational and Health Psychology, University College London, 1-19 Torrington Place, London, WC1E 7HB, UK.

s.michie@ucl.ac.uk Orcid.org/0000-0003-0063-6378

Twitter: SusanMichie

*Corresponding author: Professor Marie Johnston, Institute of Applied Health Sciences, College of Life Science and Medicine, University of Aberdeen, 2nd Floor, Health Sciences Building,, AB25 2ZD, Scotland. (e-mail: m.johnston@abdn.ac.uk).

\footnotetext{
${ }^{1}$ Now at: School of Health Sciences Edith Cavell Building, University of East Anglia, Norwich Research Park, Norwich, NR4 7TJ, UK. T: +44-1603-593874. orcid.org/0000-0002-6498-9407
} 


\section{Abstract}

\section{Objective}

Communication of the content of a behaviour change intervention $(\mathrm{BCl})$ involves clear description followed by appropriate recognition and interpretation. We investigated accuracy of recognition of $\mathrm{BCl}$ descriptions and the effects of training in the behaviour change taxonomy BCTTV1.

\section{Methods}

Materials were 166 written descriptions of two $\mathrm{BCls}$ previously written by 166 separate writers after viewing a video of the $\mathrm{BCl}$. Each of the current participants (12 naïve and 12 trained in $\mathrm{BCTTV} 1$ ) was presented with a random sample of the written descriptions and asked to form groups of descriptions they judged to be describing the same intervention. For each participant, we assessed the number of groupings of $\mathrm{BCl}$ descriptions, their purity (containing only one $\mathrm{BCl}$ ) and their differentiation (having a dominant $\mathrm{BCl}$ ).

\section{Results}

All except one participant classified the descriptions into more than two groupings. Naïve participants created significantly more groupings, fewer 'pure' groupings and less differentiated groupings (all Mann-Whitney $\mathrm{p}<.05$ ).

\section{Conclusions}

Written communications of $\mathrm{BCl}$ contents may not be recognised and interpreted adequately to support implementation. BCT taxonomy training may lead to some progress in interpreting the active content of interventions but, based on this limited study, further progress is needed if $\mathrm{BCls}$ for accurate implementation. 


\section{Introduction}

Effective behaviour change interventions ( $\mathrm{BCls}$ ) need to be clearly reported by authors and correctly interpreted by those using the evidence. Otherwise practitioners may attempt to translate into practice an intervention that does not faithfully represent the evaluated intervention; in this case, evidence incorporated into the science of behaviour change will be a confusion of valid and invalid findings. Translating $\mathrm{BCls}$ into practice or into the evidence-base can be seen as a communication process (see Figure 1) subject to social, psychological and environmental influences at every point. The $\mathrm{BCl}$ is not sent directly to the implementer but goes through a series of processes of construction and interpretation and it is the final interpretation which determines what is actually implemented or integrated into the scientific evidence base. To quote von Glasersfeld (2003): 'It's the listener, not the speaker, who determines the meaning of an utterance'. There is ample evidence from experimental studies that listeners construct the meaning of a message based on their understanding of the situation and the context in which it is presented (e.g. McNamara \& Magliano, 2009, Bransford \& Johnson, 1972, Clarke \& Johnston, 1986).

Shannon's (1949) early outline of the technical elements of the communication process continues to provide a useful framework, e.g. in examining social media communications (Swani, Milne, Brown, Assaf \& Donthu, 2017) and in education (Ibeh \& Director, 2001. It can be seen to involve a series of complex processes from the initial $\mathrm{BCl}$ to the point at which it might be implemented. The source of information (a $\mathrm{BCl}$ ) is translated into a message for communication by a sender (authors) based on social and contextual factors including their discipline, training and experience. This message is offered to potential readers through a channel of communication (e.g. publications) and may be received by someone (reader, practitioner, systematic reviewer) who may ignore it or read and interpret it within their range of competence and context. They may then choose to use, interpret or adapt the information in ways that may or may not match the original $\mathrm{BCl}$ (interpretation and 
implementation). Feedback to the original sender may then further influence the development of BCls.

Figure 1 about here

There are several points at which communication of $\mathrm{BCls}$ may result in the $\mathrm{BCl}$ as implemented being different from the one that was found to be effective in research evaluations: the source of information may be unclear if the $\mathrm{BCl}$ is poorly defined; the senders, namely the authors, may not give a report of the $\mathrm{BCl}$ that can be appropriately interpreted by the intended readership; the channel, i.e., the publication may be unavailable or fail to be delivered to intended audiences; the receiver, i.e., the reader may not interpret the $\mathrm{BCl}$ as it was originally conducted; and at its destination the $\mathrm{BCl}$ may not be implemented and/or incorporated into the evidence base appropriately.

The CONSORT (Consolidated Standards of Reporting Trials) statement (http://www.consortstatement.org/; Boutron, Moher, Altman, Schulz \& Ravaud (2008) has been helpful in specifying what needs to be reported by authors of interventions, but gives no guidance on reporting of interventions beyond, "sufficient details to allow replication including how and when they were actually administered". Recently, following agreed limitations of the standards of reporting, several approaches to improving the communication of the content of $\mathrm{BCls}$ have been developed based on consensus methods. The two main approaches are first, to improve the process of reporting and second to improve the process of interpreting what has been reported.

There is ample evidence of poor reporting of interventions in general, not only BCls. Glasziou, Meats, Heneghan \& Shepperd (2008) found that key features of interventions were adequately reported in $67 \%$ of pharmacological trials, but only $29 \%$ of non-pharmacological (mainly behavioural, rehabilitation and surgical) trials. Hoffmann, Erueti \& Glasziou (2013) found that only 59\% of nonpharmacological trials were adequately reported even after consulting the authors. $\mathrm{BCls}$ are 
particularly poorly reported; McCleary, Duncan, Stewart \& Francis (2013) found that active ingredients were less frequently reported in the titles and/or abstracts of $\mathrm{BCls}$ than of other nonpharmacological interventions.

The Template for Intervention Description and Replication (TIDieR) checklist (Hoffmann et al., 2014) was designed to facilitate the sender end of the communication process, to be used as an aid to authors, reviewers and editors to ensure that essential elements of the intervention are reported. While TIDieR specifies that the WHY (rationale or theory) and the HOW (materials and procedures) should be reported, additional work is required to fully specify the active ingredients of a $\mathrm{BCI}$. Further work is underway to develop an extension to CONSORT (CONSORT-SPI) suitable for psychological and social interventions (Montgomery et al., 2013).

Meanwhile progress has been made in developing improved methods for the receiver end of the communication by the development of a method for specifying behaviour change techniques (BCTs), the active ingredients of BCls. Following publication of the first taxonomy of BCTS by Abraham \& Michie (2008), several lists of BCTs relevant to specific behavioural contexts were published. These were brought together and developed through a process that included Delphi procedures and coding exercises with the involvement of some 400 experts plus an international advisory committee of 30 experts. The resulting list of 93 techniques with labels, definitions and examples was further developed into a hierarchical structure, the BCT taxonomy v1 (Michie et al., 2013; Cane et al., 2014). While readers using BCTTV1 have reached good agreement about the content of published $\mathrm{BCI}$ descriptions (Abraham et al, 2015), it is not possible to conclude that this shared interpretation is an accurate representation of the actual $\mathrm{BCls}$ delivered. Training programmes for $\mathrm{BCTTV} 1$ have been developed which enabled trainees to achieve better agreement with expert consensus than untrained coders in identifying BCTs in published reports of BCls (Wood, Richardson, Johnston, Abraham, Francis, Hardeman, \& Michie, 2014). 
Having demonstrated that using BCTTv1 results in a shared interpretation of published $\mathrm{BCls}$, one might also expect that it would improve reporting. Experimental work in which participants wrote descriptions of observed $\mathrm{BCls}$ (presented as videos) with and without $\mathrm{BCTTV1}$, found that descriptions generated with BCTTV1 resulted in more reliable identification of BCTs than those generated without BCTTV1 but they were not rated to be clearer or more replicable (Wood, Hardeman, Johnston, Francis, Abraham \& Michie, 2015). However, these results do not address the validity of the full communication process, i.e. did the actual $\mathrm{BCl}$ delivered, as described by these writers, result in descriptions which were interpreted by readers in a manner that matched the original $\mathrm{BCl}$ ? This is the third step in evaluating the effectiveness of written health-related information as recommended by Garner, Ning and Francis (2012).

In the study reported here, the question of accuracy is investigated by examining whether readers could recognise when descriptions were referring to the same, or different, $\mathrm{BCls}$. While recognition of a $\mathrm{BCl}$ is unlikely to be of practical significance, if a $\mathrm{BCl}$ cannot be recognised and differentiated from other $\mathrm{BCls}$, it is unlikely that it could be implemented accurately. In addition, if training readers in BCTTV1 increases the ability to recognise distinguishing features of $\mathrm{BCls}$, then they should be more able to recognise the same $\mathrm{BCl}$ presented in different reports than readers unfamiliar with BCTTV1. The research questions were:

1. Can readers accurately recognise a $\mathrm{BCl}$ from written descriptions and distinguish these descriptions from descriptions of a different $\mathrm{BCl}$ ?

2. Is accuracy of recognition improved by training in BCTTV1?

\section{Methods}

\section{Design}


Participants were recruited as part of three larger studies and completed the current task after completion of ratings of the quality, or codings of the $\mathrm{BCT}$ s in the $\mathrm{BCl}$ descriptions. The larger studies investigated the effects of training in BCTTV1 on the quality of writing (rather than reading) of $\mathrm{BCl}$ descriptions and are reported as three previous studies (see Table 1 below) (Wood et al. 2016; Michie et al., 2015). Participants were either naïve to BCTTv1 or trained (via face-to-face workshops), with competence in using BCTTv1 demonstrated by performance in post-training tests. Each participant was presented with a random sample of $\mathrm{BCl}$ descriptions of two $\mathrm{BCls}$ and asked to sort descriptions into groupings that they considered to be the same $\mathrm{BCl}$. Data were aggregated over the three study samples and analysed to examine 1) whether participants could recognise the two $\mathrm{BCls}$ from the descriptions and were therefore able to group descriptions of the same $\mathrm{BCl}$ together and 2) whether participants trained in BCTTV1 were more accurate than untrained ('naïve') participants.

\section{Materials}

A total of 166 descriptions (42, 85 and 78 aggregated from studies 1, 2 and 3 respectively) of $\mathrm{BCls}$ were generated by writers who had viewed videos of one of two $\mathrm{BCls}$ being delivered. Details of the writers are reported in Michie et al., (2015). Each video showed a smoking cessation intervention to ensure that similarity of $\mathrm{BCls}$ was not simply judged on the basis of the behaviour being addressed. The videos were similar in length (approximately nine minutes) and showed a Stop Smoking Specialist delivering a smoking cessation intervention to a client. The videos were selected for this study because they included a range of frequently observed and clearly delivered BCTs.

In order to produce the descriptions, writers watched one of the two videos. Whilst watching the video, writers were instructed to write notes about the 'active components' (i.e. content delivered that was likely to change behaviour). Each video was only shown once. Following the video, participants were then given 15 minutes to write a description in such a way that: a) the active 
components being delivered in the intervention could be understood and, b) the intervention could be replicated by someone else. While the task differed from normal $\mathrm{BCl}$ description reporting, normal reporting would not permit assessment of accuracy. The constraints were imposed for practical reasons and to ensure that the descriptions of the two $\mathrm{BCls}$ were all written under the same conditions to reduce the likelihood that extraneous factors could be used to discriminate the BCls.

\section{Participants}

Participant details are given separately for each study (see Table 1). There were two groups of participants, naïve regarding BCTTV1 and trained in the use of BCTTV1:

1. Naïve (to BCTTv1): were 12 practitioners unfamiliar with BCTTV1. Since they were rating descriptions of a smoking cessation intervention, they were recruited from the National Centre for Smoking Cessation and Training (NCSCT) database (www.ncsct.co.uk/), an online training resource designed for smoking cessation advisors to support delivery of smoking cessation interventions. To help ensure unfamiliarity with BCTTV1, only practitioners who had registered with the NCSCT but who had not yet started their training with the NCSCT were invited to take part.

2. Trained (in BCTTv1): were 12 behaviour change researchers and practitioners, who had previously been trained via BCTTV1 group tutorial training (Wood, et al. 2014) and demonstrated competence (assessed as satisfactory reliability and validity against expert consensus).

The task was estimated to take up to one day. Invitations were sent with an offer of an honorarium of $£ 280$ on completion of the task. 


\section{Procedure}

All participants had completed a task to assess reporting quality of the descriptions ${ }^{2}$ (see Wood, et al., 2016) before commencing this study.

Each participant received a random selection of descriptions (using a random number generator). For Study 1 they each received 21 of the 42 descriptions; for Study 2 they received 42 or 43 of the 85 descriptions; and for Study 3 they received 39 of the 78 descriptions. Participants were given no information about how the descriptions had been written.

Participants were sent a link via email instructing them to complete an open-sort grouping task using an online computer programme (www.optimalworkshop.com). Instructions guided participants to 'group descriptions according to those that described the same intervention'. Descriptions were displayed in a list located on the left-hand-side of the participants' screens. Participants were instructed to 'drag and drop' descriptions from the list into the middle of their screen to begin grouping; dropping descriptions on top of one another, placed them into the same grouping. No restrictions were placed on the number of groupings that could be made and participants were given the option to label their groupings if they wanted to. Descriptions were programmed so that they were presented to participants in a random order. There was no time limit set for the task and participants were debriefed about the study following completion.

\section{Scoring and statistical analysis}

Figure 2 shows an example of responses from one respondent with the scoring illustrated.

Figure 2 about here

\footnotetext{
${ }^{2}$ In the previous task, naïve participants had rated the clarity and quality of the descriptions while trained participants had coded the BCTs in each description.
} 
1. Number of groupings: The number of groupings created was calculated for each participant; if participants achieved complete accuracy, there would be two groupings, with one grouping containing all descriptions pertaining to $\mathrm{BCl}_{\mathrm{a}}$ and no descriptions generated from $\mathrm{BCl}_{\mathrm{b}}$ and the other grouping containing all description pertaining to $\mathrm{BCl}_{\mathrm{b}}$ and no descriptions generated from $\mathrm{BCl}_{\mathrm{a}}$. Over all three studies, over all 24 participants, the probability of deviation from the 'correct' number i.e. 2 , was tested using a binomial test with the a priori probability of a participant making 2 groupings set at 0.5. Naïve and trained participants were compared using Mann-Whitney U-test.

2. Purity of groupings: $A$ pure grouping is one which included only descriptions of $\mathrm{BCl}_{\mathrm{a}}$ or only $\mathrm{BCl}_{\mathrm{b}}$. Since participants produced different numbers of groupings, the proportion of pure groupings was calculated for each participant. Higher scores indicate more pure groupings. The data for naïve and trained participants were compared using Mann-Whitney U-test.

3. Differentiation of $\mathrm{BCls}$ : While the number of $\mathrm{BCls}$ was different for each study, naïve and trained participants classified the same number of descriptions. The extent to which a participant differentiated $\mathrm{BCl}_{\mathrm{a}}$ and $\mathrm{BCl}_{\mathrm{b}}$ was calculated as the sum over all of their groupings of the absolute difference between the numbers of each $\mathrm{BCl}$ which had a possible range from zero indicating that all groupings had an equal number of each $\mathrm{BCl}$, to a maximum equal to the number of $\mathrm{BCls}$ classified indicating that all groupings had contained only one of the two BCls. So for example, in Figure 2, the participant produced 4 groupings: ' $A$ ' contained $3 \mathrm{BCl}_{\mathrm{a}}$ and $1 \mathrm{BCl}$. ' $\mathrm{B}$ ' had $5 \mathrm{BCl}_{\mathrm{a}}$ and $1 \mathrm{BCl}_{\mathrm{b}}$, ' $\mathrm{C}$ ' had 2 $\mathrm{BCl}_{\mathrm{a}}$ and $1 \mathrm{BCl}_{\mathrm{b}}$ and ' $\mathrm{D}$ ' had $4 \mathrm{BCl}_{\mathrm{a}}$ and $3 \mathrm{BCl}_{\mathrm{b}}$; their score would be $8(2+4+1+1)$. Higher scores indicate more differentiation. Mann-Whitney U-tests were used to compare data from naïve and trained participants.

\section{Results}

\section{Number of groupings}


The median number of groupings generated by participants was 5 (range 2 to 8 ) groupings (see Figure 3). All except one participant made more than 2 groupings; the binomial test was significant at $p<.0001$. Naïve participants generated more groupings than trained participants [median naïve $=$ 6.5 (range 4 to 8); median trained=4.5 (range 2 to 8); Mann-Whitney $U=35.5, p<.05$ ].

Figure 3 about here

\section{Purity of groupings}

The one participant categorising the descriptions into two groupings had one pure grouping of $13 \mathrm{BCls}$ but the other grouping had a mixture of 20 of one $\mathrm{BCl}$ and 10 of the other $\mathrm{BCl}$. The median proportion of pure groupings was 0.25 for naïve and 0.50 for trained participants (Mann Whitney $U=30, p \leq 0.05$ ). The trained participants were therefore more successful in producing pure groupings.

\section{Differentiation of $\mathrm{BCls}$}

The median differentiation score for naïve participants was 20 and for trained participants and 11.5 for naïve participants (Mann Whitney $U=30.5, p \leq 0.05$ ). Trained participants were more successful in differentiating the two $\mathrm{BCls}$ reported in the descriptions.

\section{Discussion}

This study was innovative in investigating whether $\mathrm{BCls}$ could be recognised accurately, whereas previous studies have concentrated on establishing reliability between coders of interventions (Abraham \& Michie, 2008; Michie et al., 2013; Abraham et al., 2015). While achieving agreement about the content of a $\mathrm{BCl}$ based on a written report is valuable, for an effective $\mathrm{BCl}$ to be implemented readers need to interpret its content accurately. All of the participants in the current study were involved in implementing $\mathrm{BCls}$ in practice, or in research on $\mathrm{BCls}$, or both. Interpreting the content of $\mathrm{BCl}$ descriptions was therefore an essential part of their skills. Understanding the 
elements and the delivery of a $\mathrm{BCl}$ involves several layers of complex interpretation, but we chose to investigate the most basic level - could they tell one $\mathrm{BCl}$ from another?

Even so, we found that participants could not reliably recognise and distinguish the minimum i.e. two $\mathrm{BCls}$, from descriptions. All except one participant created more than two $\mathrm{BCl}$ groupings and even that person did not distinguish the $\mathrm{BCls}$ as one of their groupings was very mixed. Participants with proven competence in reliably coding BCTs had fewer groupings than naïve participants but even they had a median of over four groupings. Nevertheless the trained participants were more successful in producing 'pure' groupings which contained only one of the two BCls and their groupings were more likely to have a preponderance of one or other $\mathrm{BCl}$ showing that they were better at differentiating the two $\mathrm{BCls}$.

The communication of the content of the $\mathrm{BCls}$ has clearly failed in this task as participants could not reliably tell one $\mathrm{BCl}$ from another based on the descriptions. If this were the level of success achieved in routine communication of $\mathrm{BCls}$, then reliable implementation would be unlikely to occur. Some success in implementation might be achieved by delivering what the two $\mathrm{BCls}$ share, but the $\mathrm{BCls}$ in the current study differed in the type and number of $\mathrm{BCTs}$ and so recognising the differences between them would be necessary for full implementation. Even so, while successful recognition of the $\mathrm{BCl}$ is necessary, it is unlikely to be sufficient to achieve 'adequate' implementation in real world delivery of $\mathrm{BCls}$, however 'adequate' is defined.

Normal reporting of $\mathrm{BCl}$ content in publications is likely to be rather better than could be achieved in the descriptions written in these artificial conditions which were constrained for practical reasons and to ensure experimental control. The descriptions were written after writers had watched videos of the $\mathrm{BCls}$ only once and then wrote their descriptions in a limited amount of time. This is a far cry from the circumstances in which researchers or intervention developers gain familiarity with an intervention, which would include reading and discussion iteratively over time, rather than a one-off quick observation. $\mathrm{BCl}$ s are likely to be communicated via a range of methods which enable reliable 
implementation, including written manuals, DVDs, internet portals, personal supervision etc. The artificiality of the current task was the result of the need to have multiple descriptions of exactly the same $\mathrm{BCl}$ in order for participants to match one $\mathrm{BCl}$ description to another and to ensure that all descriptions were written under similar conditions so that differentiation of the $\mathrm{BCls}$ was not enhanced by extraneous or contextual factors.

Guidelines on the reporting of interventions, such as CONSORT and TIDieR (Hoffmann et al., 2014), are likely to improve the general reporting of the context and delivery of interventions, but do not address the reporting of the 'active' content which was the focus of the written descriptions provided in the current study. While the general context and delivery may be important in ensuring the success of an intervention, without replicating active content a $\mathrm{BCl}$ will not translate the behaviour change reported into actual implementation in practice.

In the current study, BCTTv1 expertise appeared to enhance the recognition of $\mathrm{BCls}$, with trained participants creating more pure, differentiated groupings of BCls. Trained participants also reported more $\mathrm{BCl}$ expertise (see Table 1) and it may be the combination of this expertise with the BCTTV1 training that made them better at differentiating $\mathrm{BCls}$. In either case there are implications for implementation of written reports of $\mathrm{BCls}$. Practitioners with expertise and BCTTV1 training appear to be more likely to interpret the $\mathrm{BCl}$ correctly and therefore to implement the $\mathrm{BCl}$ appropriately than those without such expertise and training. Researchers interpreting research findings, including those conducting systematic reviews, may be more accurate if they have expertise in $\mathrm{BCls}$ and BCTs in addition to specific disciplinary or systematic review expertise.

There are several limitations to this study, mostly incurred through the need to assess accuracy without unduly burdening participants. The need to set an accuracy standard meant that it was not possible to use descriptions of $\mathrm{BCls}$ written under normal reporting conditions. By contrast, existing reports of $\mathrm{BCls}$ such as published reports or manuals are written under more satisfactory conditions, it is not possible to ascertain their validity. 
The naïve and trained participants in the current study were inevitably recruited in rather different ways and the two groups will have differed on more characteristics than simply their knowledge and expertise in using BCTTV1. As noted above, they also differed in $\mathrm{BCl}$ expertise. Thus caution is required in interpreting differences between these two groups. Nevertheless the main findings of $\mathrm{BCls}$ not being recognisable was true overall and did not depend on group differences.

This study only investigated 'recognition', a necessary but not sufficient condition for BCl interpretation. Without recognition it is unlikely that a $\mathrm{BCl}$ could be implemented effectively, but much more than recognition is required for faithful replication of a successful $\mathrm{BCl}$. Even if recognised and interpreted appropriately, implementation may fail due to lack of skills, resources or other aspects of the implementation context. Specification of the competences required to deliver $\mathrm{BCls}$ includes more generic basic competences in delivering communications to a client group as well as basic knowledge and skills in assessing need for behaviour change. (Dixon \& Johnston, in submission; http://www.healthscotland.com/documents/4877.aspx )

In conclusion, having outlined the necessary processes for the successful communication of a $\mathrm{BCl}$ in Figure 1, it is not clear how well each stage is achieved and how this might be improved. We now have a taxonomy, in which each BCT has a label, and a shared language for describing BCls. We encourage writers of $\mathrm{BCls}$ to use the $\mathrm{BCT}$ labels when reporting their interventions. This will enhance the accuracy with which taxonomy-trained readers can interpret intervention descriptions and reproduce $\mathrm{BCls}$. From the current study, it would appear that expertise and training in $\mathrm{BCT}$ and $\mathrm{BCls}$ improves the reader's ability to interpret a $\mathrm{BCl}$ which is surely a first step in implementing it into research and practice.

Acknowledgements: This work was supported by the MRC via its Methodology Panel: 'Strengthening evaluation and implementation by specifying components of behaviour change interventions' under grant number G0901474/1 


\section{References}

Abraham, C. \& Michie, S. (2008) A taxonomy of behavior change techniques used in interventions. Health Psychology, 27(3):379-87. https://doi.org/10.1037/0278-

$\underline{6133.27 .3 .379}$

Abraham, C., Wood, C.E., Johnston, M., Francis, J., Hardeman, W., Richardson, M. \& Michie, S. (2015) Reliability of identification of behavior change techniques in intervention descriptions. Annals of Behavioral Medicine, 49(6), 885-

900. https://doi.org/10.1007/s12160-015-9727-y

Boutron, I., Moher, D., Altman, D.G., Schulz, K.F., \& Ravaud, P. (2008) Extending the CONSORT Statement to Randomized Trials of Nonpharmacologic Treatment: Explanation and Elaboration. Annals of Internal Medicine, 148:295-309. https://doi.org/10.7326/0003$\underline{4819-148-4-200802190-00008}$

Bransford, J. D., \& Johnson, M. K. (1972). Contextual prerequisites for understanding: Some investigations of comprehension and recall. Journal of verbal learning and verbal behavior, 11(6), 717-726. https://doi.org/10.1016/S0022-5371(72)80006-9

Cane, J., Richardson, M., Johnston, M., Ladha, R., \& Michie, S. (2015). From lists of behaviour change techniques (BCTs) to structured hierarchies: comparison of two methods 
of developing a hierarchy of BCTs. British Journal of Health Psychology, 20(1), 130150. https://doi.org/10.1111/bjhp.12102

Clarke, A. \& Johnston, M. (1986) Use of a medical 'schema' in facilitating access to understanding in psychology. Medical Education, 20, 410416. https://doi.org/10.1111/j.1365-2923.1986.tb01186.x

Dixon, D. \& Johnston, M., (in submission) What Competences are required to deliver behaviour change interventions? Development of a Health Behaviour Change Competency Framework.

Garner, M., Ning, Z., \& Francis, J. (2012). A framework for the evaluation of patient information leaflets. Health Expectations, 15(3), 283-294. https://doi.org/10.1111/j.1369$\underline{7625.2011 .00665 . \mathrm{X}}$

Glasziou P, Meats E, Heneghan C, Shepperd S. (2008). What is missing from descriptions of treatment in trials and reviews? BMJ, 336:1472-

4. https://doi.org/10.1136/bmj.39590.732037.47

Hoffmann, T., Erueti, C., \& Glasziou, P. (2013) Poor description of non-pharmacological interventions: analysis of consecutive sample of randomised trials. BMJ, 347:f3755.https://doi.org/10.1136/bmj.f3755 
Hoffmann, T. C., Glasziou, P. P., Boutron, I., Milne, R., Perera, R., Moher, D., Johnston, M.... \& Michie, S. (2014). Better reporting of interventions: template for intervention description and replication (TIDieR) checklist and guide. BMJ,

348. https://doi.org/10.1136/bmj.g1687

Ibeh, C. C., \& Director, P. S. U. (2001). 'Research, Report Writing, and Representation': The Most Viable 3Rs for Critical Thinking and Effective Communication Skills in SMET Education. Age, 6, 1.

McCleary, N., Duncan, Stewart \& Francis (2013) Active ingredients are reported more often for pharmacologic than non-pharmacologic interventions: an illustrative review of reporting practices in titles and abstracts. Trials, 14,146. https://doi.org/10.1186/1745-6215$\underline{14-146}$

McNamara, D. S., \& Magliano, J. (2009). Toward a comprehensive model of comprehension. Psychology of learning and motivation, 51, 297-

384. https://doi.org/10.1016/S0079-7421(09)51009-2

Michie, S., Richardson, M., Johnston, M., Abraham, C., Francis, J., Hardeman, W., ... \& Wood, C. E. (2013). The behavior change technique taxonomy (v1) of 93 hierarchically clustered techniques: building an international consensus for the reporting of behavior change interventions. Annals of Behavioral Medicine, 46(1), 8195. https://doi.org/10.1007/s12160-013-9486-6 
Michie, S., Wood, C.E., Johnston, M., Abraham, C., Francis, J. \& Hardeman, W. (2015)

Behaviour Change Techniques: The Development and Evaluation of a Taxonomic Method for Reporting and Describing Behaviour Change Interventions. NIHR Health Technology Assessment 06/92/57

Montgomery, P., Grant, S., Hopewell, S., Macdonald, G., Moher, D., Michie, S., \& MayoWilson, E. (2013). Protocol for CONSORT-SPI: an extension for social and psychological interventions. Implementation Science, 8(1), 99. https://doi.org/10.1186/1748-5908-8-99

Shannon, C. E. (1949). Communication in the presence of noise. Proceedings of the IRE, 37(1), 10-21. https://doi.org/10.1109/JRPROC.1949.232969

Swani, K., Milne, G. R., Brown, B. P., Assaf, A. G., \& Donthu, N. (2017). What messages to post? Evaluating the popularity of social media communications in business versus consumer markets. Industrial Marketing Management, 62, 77-

87. https://doi.org/10.1016/j.indmarman.2016.07.006

Von Glasersfeld, E. (2003). The constructivist view of communication. In: Müller, A. \& Müller, K. H. (eds.) An unfinished revolution. Edition Echoraum: Vienna, pp. 351-360. www.univie.ac.at/constructivism/EvG/papers/276.pdf

Wood, C.E., Hardeman, W., Johnston, M., Francis, J., Abraham, C. \& Michie, S. (2016) Reporting Behaviour Change Interventions (BCIs): The effect of using BCTTv1 on 
writing of descriptions of BCIs. Implementation Science, 11.84. doi 10.1186/s13012-0160448-9.

Wood, C.E., Richardson, M., Johnston, M., Abraham, C., Francis, J., Hardeman, W. \& Michie, S. (2014). Applying the Behaviour Change Technique (BCT) Taxonomy v1: A study of coder training. Translational Behavioral Medicine: Practice, Policy, Research. doi: 10.1007/s13142-014-0290-z. 


\section{Figure Captions}

Figure 1: The communication process of reporting behaviour change interventions ( $\mathrm{BCls}$ ) by authors, interpreting by readers with resulting implementation of BCls (adapted from Shannon, 1949)

Figure 2: Scoring illustration: Example of one participant who created four groupings with 4, 6, 3 and $7 \mathrm{BCl}$ descriptions.

Figure 3: Number of groupings produced by naïve and trained participants. 
Table 1: Summary of participant characteristics in studies 1, 2 and 3

\begin{tabular}{|l|l|l|l|l|l|l|}
\hline Study & $\begin{array}{l}\text { Number of } \\
\text { descriptions }\end{array}$ & Participants & $\mathrm{N}$ & Mean age & $\begin{array}{l}\mathrm{N} \\
\text { doctorate/ } \\
\text { practitioner }\end{array}$ & $\begin{array}{l}\text { Self-rated } \\
\text { expertise in BCl: } \\
\text { Mean (s.d.) on } \\
\text { scale from 1-5 }\end{array}$ \\
\hline 1 & 42 & naïve & 4 & 30.50 & $0 / 4$ & $2.00(1.47)$ \\
\cline { 3 - 7 } & & trained & 4 & 32.25 & $3 / 1$ & $3.50(0.37)$ \\
\hline 2 & \multirow{2}{*}{85} & naive & 4 & 32.50 & $0 / 4$ & $2.00(1.22)$ \\
\cline { 3 - 7 } & & trained & 4 & 31.75 & $4 / 1$ & $3.44(0.59)$ \\
\hline \multirow{2}{*}{3} & \multirow{2}{*}{78} & naïve & 4 & 31.50 & $0 / 4$ & $2.26(0.82)$ \\
\cline { 3 - 7 } & & trained & 4 & 44.25 & $4 / 2$ & $3.50(0.88)$ \\
\hline
\end{tabular}




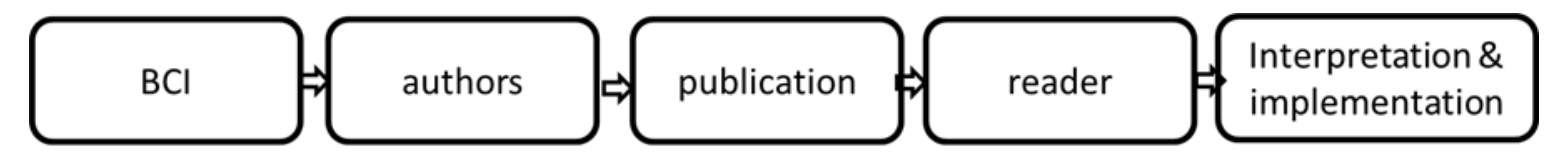




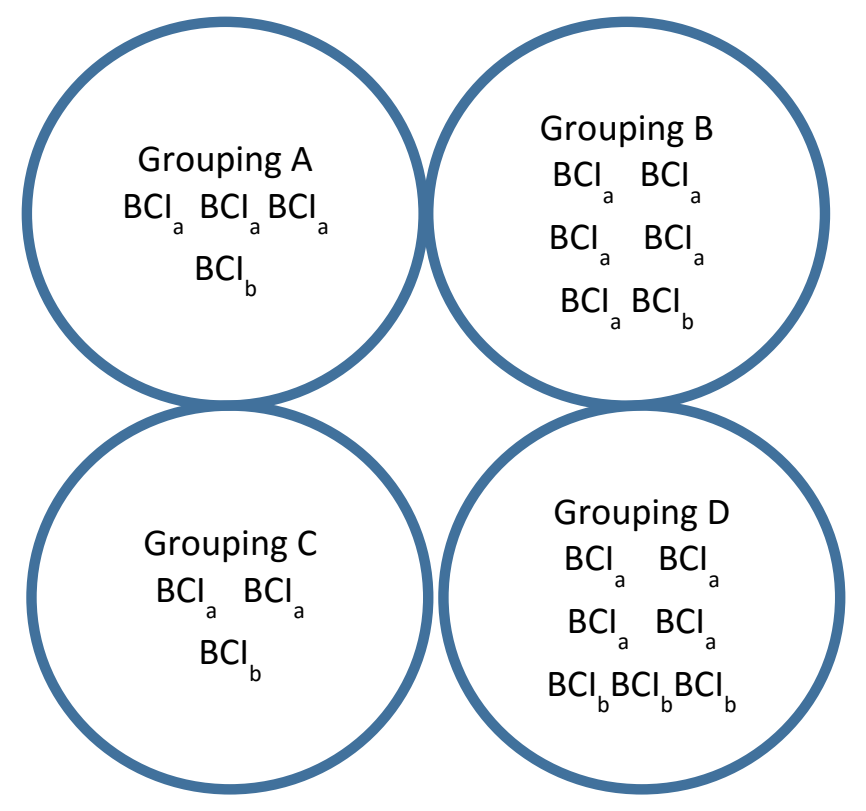

The scores are: number of groupings $=4$; number of pure groupings $=0$; differentiation $=$ $A(3-1)+B(5-1)+C(2-1)+D(4-3)=8$ 


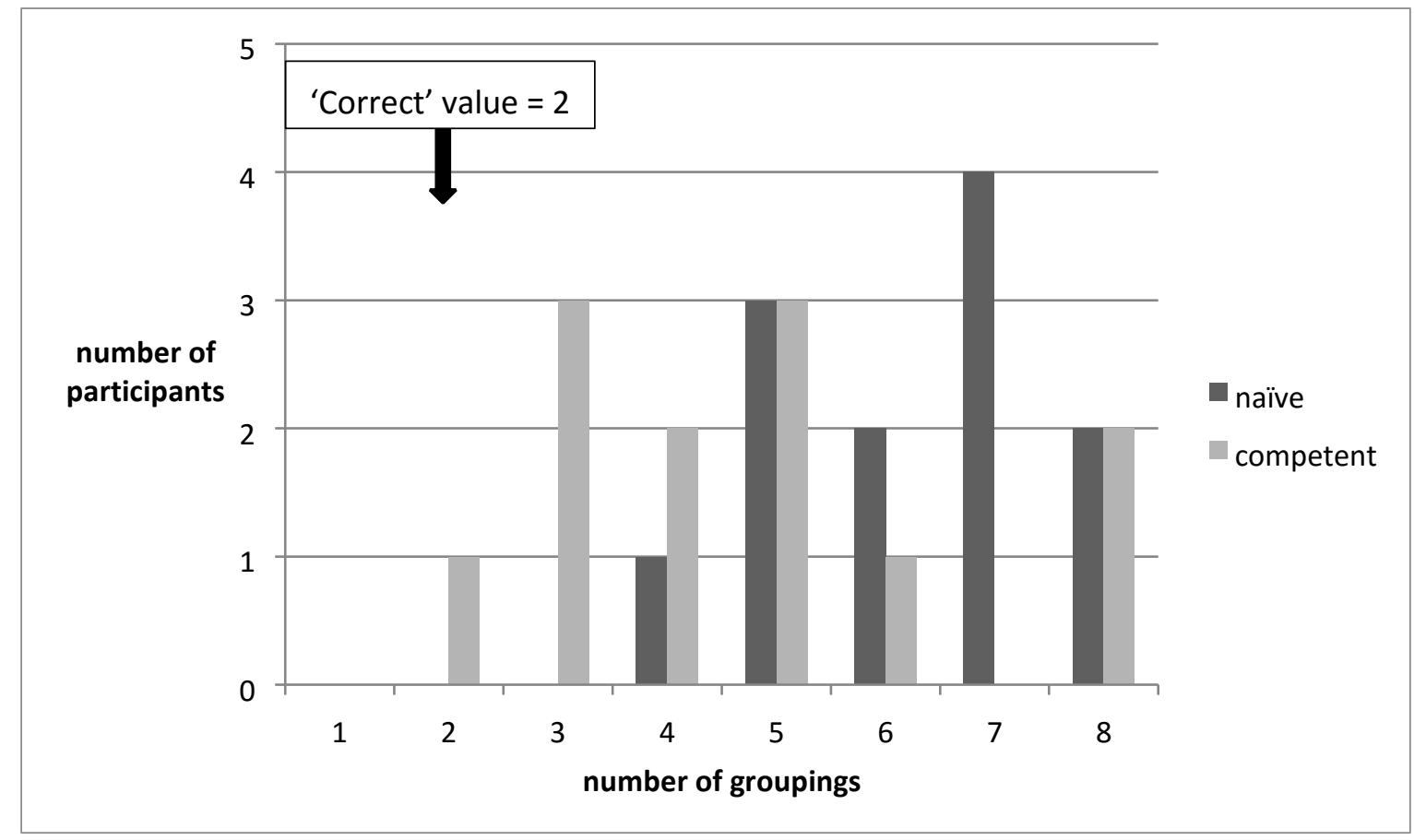

